\title{
Experimental study of noise mitigation measures on a slab track
}

\author{
Xianying Zhang*, Hongseok Jeong, David Thompson, Giacomo Squicciarini \\ Institute of Sound and Vibration Research, University of Southampton, Southampton SO17 1BJ, UK \\ *Corresponding author: xianyingzhang96@gmail.com
}

\begin{abstract}
Slab track is generally noisier than conventional ballasted track, so noise control measures that can be applied to a slab track are of great importance. Several noise control treatments have been studied under controlled conditions through experiments on a 1:5 scale model slab track with and without the presence of a train body. These treatments consist of absorptive rubber mats applied to the surface of the slab and a low noise barrier introduced close to the track. The noise reduction is evaluated experimentally by using a reciprocal method and compared with the results of numerical simulations. The insertion loss spectra of these treatments have been combined with predicted train pass-by spectra to determine the potential overall noise reductions. It has been found that the absorptive treatment alone has only a small effect on the radiated noise from the track. This is increased by the presence of the train body leading to a reduction of up to $2-3 \mathrm{~dB}$ at a standard receiver height of $1.2 \mathrm{~m}$, which suggests that the absorptive layer controls reflections between the car body and the track. All the treatments considered have a greater effect on the noise radiated by the lateral vibration of the rail than on that from the vertical vibration. Their effectiveness mostly increases, by between roughly 0.5 and $1.5 \mathrm{~dB}$, as the train speed is increased from 80 to $300 \mathrm{~km} / \mathrm{h}$. As expected, the noise barrier is more effective at lower receiver positions than at higher ones but its effectiveness is reduced by 1-2 $\mathrm{dB}$ by the presence of the train body. However, in combination with the absorptive treatment, its effectiveness increases when the train body is present. This shows the importance of including of the presence of the train body in evaluating the effects of acoustic treatments in the track.
\end{abstract}

Keywords: slab track, noise mitigation, absorptive treatment, low-height barrier, finite element method, boundary element method

\section{Introduction}

Although conventional railway track is constructed on ballast, modern track construction for both high-speed and urban networks is increasingly based on concrete slab track designs. These 
have experienced considerable expansion in recent years, especially in China. Slab tracks generally have lower maintenance costs, excellent stability and are particularly suitable for high speed operation [1]. However, slab track is often noisier than ballasted track [2]. The most important source of environmental noise from railways is rolling noise, which is produced by vibration of the track and wheel induced by their combined surface roughness at the wheel/rail contact [3]. For a slab track, the absence of acoustic absorption from the ballast leads to an increase in radiated noise. Moreover, as slab tracks often have softer rail fastenings, and consequently lower track decay rates, the noise emitted by the rail can be higher than on ballasted tracks. Together, these effects lead to differences in sound power level of 1-2 dB compared with a ballasted track with soft rail pads or 4-5 $\mathrm{dB}$ compared with a ballasted track with stiff pads [2]. In terms of sound pressure level, these differences can range from 0 to $8 \mathrm{~dB}$ depending on the receiver location and the ground conditions adjacent to the track [4]. It is therefore particularly important to develop suitable noise control measures that can be applied to slab tracks.

A review of noise control measures for rolling noise was given in [5]. Although this focussed on ballasted track, the same control measures are also generally applicable to slab tracks. Rail dampers are particularly effective on tracks with a low initial decay rate $[6,7,8]$ and can therefore be expected to be suitable for slab tracks. Despite this, there appears to be reluctance from infrastructure authorities to install rail dampers on high-speed lines.

In $[9,10]$ a slab track was modified by incorporating an embedded rail with a smaller section and stiff embedding material. Calculations indicated that this track could produce between 4 and $6 \mathrm{~dB}(\mathrm{~A})$ less noise than a reference ballasted track. Integral barriers attached to the slab track gave a further reduction of $6 \mathrm{~dB}$. By applying an absorptive treatment on this slab track additional reductions of $2 \mathrm{~dB}$ were achieved.

An absorptive treatment was tested on slab tracks in Germany in the 1990s [11,12] and found to give noise reductions of up to $6 \mathrm{~dB}$. This treatment included a raised section that acted like a small integral noise barrier; where this was omitted the noise reduction was lowered to about $4.5 \mathrm{~dB}$ and, for a more limited treatment which left the rail more exposed, the reduction was only $3 \mathrm{~dB}[5,11]$. 
Weber and Sburlati [13] studied several options to reduce the noise from a slab track fitted with soft rail fastenings. Rail dampers were shown to offer a reduction of $4 \mathrm{~dB}$, and it was assumed that absorptive panels installed between the rails could give a reduction of $3 \mathrm{~dB}$. Rail grinding was also applied to deal with rail corrugation. In [14] a study was carried out on a slab track section of the Athens Metro. Three mitigation measures were applied, individually and together: rail dampers, absorbing panels on the track, and absorbing noise barriers of height 1.1-1.2 m above the railhead located at $2.6 \mathrm{~m}$ from the track centre. At a microphone position $7.5 \mathrm{~m}$ from the track centre, the rail dampers gave a reduction of $1.5 \mathrm{~dB}$, the absorbing panels $2 \mathrm{~dB}$ and the barriers $6.6 \mathrm{~dB}$. The train speed was $60 \mathrm{~km} / \mathrm{h}$.

Zhao et al. [15] studied the sound absorption of various types of porous sound-absorbing concrete and found that an optimal performance was obtained with an aggregate gradation of around 1-3 mm. Based on their findings, porous sound-absorbing concrete slabs were manufactured and applied on a test section of slab track. From field measurements of noise from passing trains, noise reductions were obtained which increased from $2.5 \mathrm{~dB}$ at $80 \mathrm{~km} / \mathrm{h}$ to $4 \mathrm{~dB}$ at $200 \mathrm{~km} / \mathrm{h}$.

Kim and Kim [16] studied a noise absorbing block on a slab track using finite element simulations and field measurements. It was shown that the noise level was reduced by more than $3 \mathrm{~dB}(\mathrm{~A})$ at $3.3 \mathrm{~m}$ away from the centre of the track, with reductions observed between 300 $\mathrm{Hz}$ and $1250 \mathrm{~Hz}$. Shin et al. [17] measured equivalent sound pressure levels from passing trains, with and without absorbing blocks. The measurement was conducted at different locations, and it was shown that the insertion loss was around 4-5 dB at a point near the track. However, no details were provided about the exact measurement positions or details of the blocks. Bryne [18] measured noise reductions due to absorbing rubber mats applied on a slab track on the tram network in Dublin. A noise reduction of up to $4.8 \mathrm{~dB}(\mathrm{~A})$ was found, with acoustic attenuation seen at frequencies above $400 \mathrm{~Hz}$.

Absorptive treatments applied on a slab track can therefore be seen to lead to noise reductions varying between 2 and $5 \mathrm{~dB}$ in different applications. In most previous studies, field test results are presented but it is not possible to identify the relative contributions of the track and wheels to the initial noise or the noise reduction. Moreover, in many cases there is no information about the acoustic properties of the absorptive treatments. The extent to which the treatment acts to shield the rail as well as absorb sound has also not been investigated. 
The aim of the current paper is to study the effects of absorptive treatments applied to a slab track in controlled conditions through laboratory experiments on a 1:5 scale model. In addition, a low-height barrier close to the track is studied alone and in combination with the absorptive treatments. The work concentrates on the effect of these different measures on the noise radiated by the rail, which is studied separately for vertical and lateral vibration. The influence of the car body in reflecting the sound radiated by the rail, and thereby modifying the performance of the control measures, is also assessed. The model track, the configurations evaluated and the measurement method are described in Section 2. In Section 3 numerical models are briefly introduced which are used for comparison with the measured results. Results are given and discussed in Section 4 in the form of insertion loss spectra. In Section 5 they are combined with predictions of rolling noise to estimate the effect on train pass-by noise. Conclusions are given in Section 6.

\section{Measurements}

Laboratory measurements have been performed on a 1:5 scale model slab track installed in an anechoic chamber to study the effect of the noise mitigation measures on the noise radiation from the rail. In a mechanical scale model, the principle followed is to reduce all dimensions by the scale factor while retaining the same material properties. As a result, the natural frequencies of the system are increased by the scale factor (stiffness reduces by the scale factor and mass by the scale factor to the power 3). To interpret the results in terms of full-scale behaviour it is necessary to adjust the frequency downwards by the scale factor. The same applies to the acoustic field.

\subsection{Track and configurations tested}

The 1:5 scale model slab track was constructed from reinforced concrete and is shown in Figure 1. The rails were of a type used for miniature railways; they are made of steel and are approximately 1:5 scale representations of mainline rail. Their height is $35 \mathrm{~mm}$, the width of the foot is $31 \mathrm{~mm}$ and they have a mass of $3.4 \mathrm{~kg} / \mathrm{m}$. Beneath the rail at intervals of $0.13 \mathrm{~m}$ were two layers of rubber pad separated by an intermediate steel plate giving a total height of $15 \mathrm{~mm}$ above the slab. The model track is $2 \mathrm{~m}$ long and the slab has a thickness of $0.12 \mathrm{~m}$, a width of $0.7 \mathrm{~m}$ at the lower part and $0.5 \mathrm{~m}$ at the upper part. This length was chosen for practical reasons. 
The rails were held in place using spring clips. Although their stiffness is not necessarily representative of a full-scale track, their main function is to apply a preload to ensure good contact between the rail and the rail pads. As in a full-scale track, the stiffness of the spring clips is much smaller than that of the rail pads.

The point and transfer mobilities of the rail were measured using impact excitation and are presented in Figure 2. Figure 2(a) shows the point mobilities on the rail head for vertical and lateral directions. These were measured at the centre of the rail at mid-span between two fastenings. At low frequencies these are stiffness controlled, rising to a peak at $500 \mathrm{~Hz}$ for the lateral direction and $800 \mathrm{~Hz}$ for the vertical direction. These are effectively the resonances of the rail mass on the support stiffness which form the cut-on frequencies of waves in the rail [3]. Because of the finite length of the rail a number of resonance peaks are seen in the mobilities above these cut-on frequencies.

Figure 2(b) shows the spatial average of the transfer mobilities from the central point to 18 points distributed along the rail. These averages are determined as the square root of the average of the squared magnitude of the transfer mobilities.

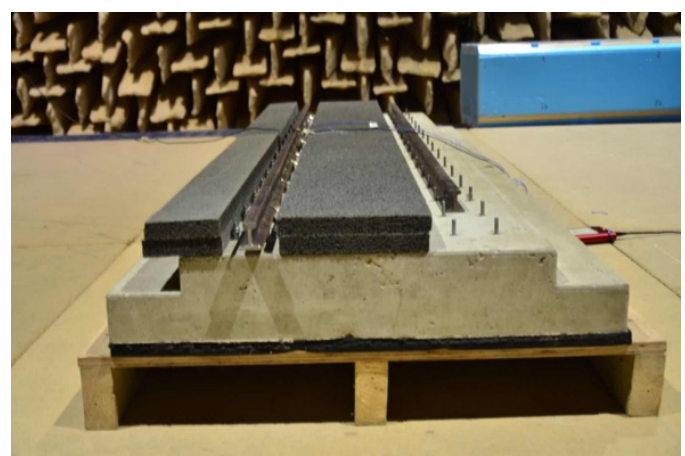

(a)

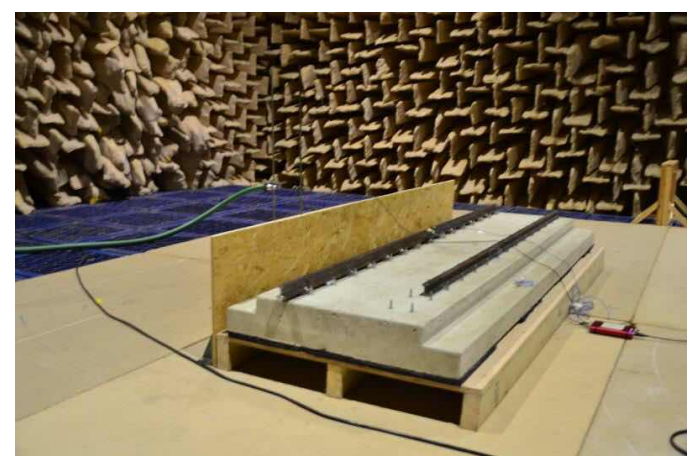

(b)

Figure 1 Slab track model and noise mitigation measures studied in the measurements. (a) Absorptive treatment; (b) barrier. 


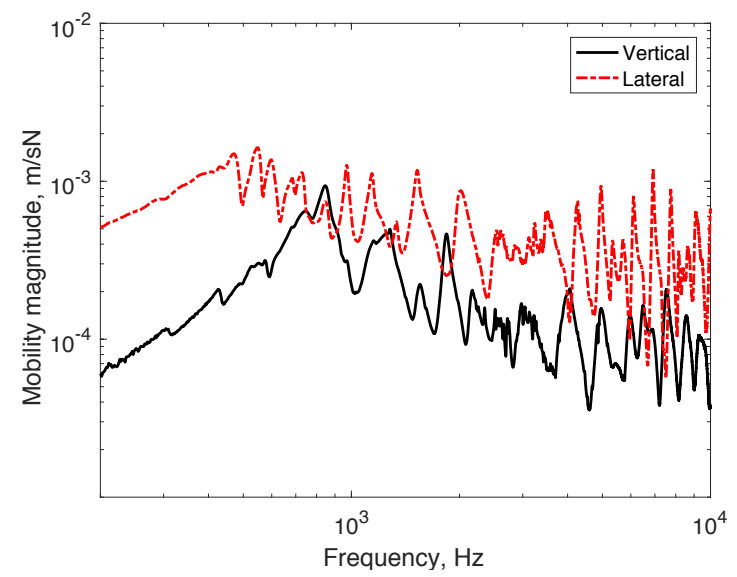

(a)

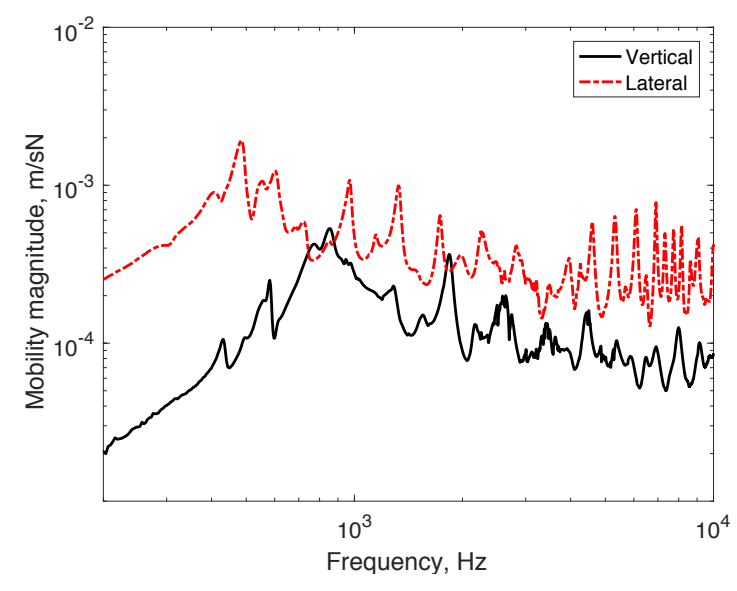

(b)

Figure 2 Comparison of the point mobility and transfer mobility for vertical motion and lateral motion. (a) Point mobilities; (b) spatially averaged mobility

As seen in Figure 1, the model slab track was installed in an anechoic chamber. Wooden panels were placed beneath the track system on top of the metal grid flooring system, to introduce a reflecting ground. The rail head was $0.29 \mathrm{~m}$ above this surface.

Examples of the noise mitigation measures considered are also shown in Figure 1. Porous rubber panels with a thickness of $24 \mathrm{~mm}$ (single layer) or $48 \mathrm{~mm}$ (double layer) were located on top of the slab, both between the rails and on the outer edges of the slab, as shown in Figure 1(a). In the double layer configuration, the top of the porous material was almost level with the top of the rail head; it was located $40 \mathrm{~mm}$ away from the rail centreline on either side. In addition, a barrier of dimensions $2 \mathrm{~m} \times 0.4 \mathrm{~m}$, constructed of $12 \mathrm{~mm}$ thick chipboard, was mounted vertically alongside the track slab, as shown in Figure 1(b). This thickness is sufficient to avoid transmission through the panels (giving an insertion loss of at least $30 \mathrm{~dB}$ in the frequency range considered). Its upper edge was $0.11 \mathrm{~m}$ above the top of the rail, and it was located $0.4 \mathrm{~m}$ away from the centre of the track. This barrier was tested on its own and in combination with the porous material.

The absorption coefficient of the porous rubber mats has been measured in an impedance tube and is shown in Figure 3. Also shown is the result obtained from a poro-elastic model [20] using the parameters listed in Table 1. Figure 3 shows good correspondence between the predicted and measured absorption, indicating the validity of the chosen parameters in Table 
1. Although this set of parameters is not unique, it can be expected that any reasonable set of parameters matching the measured absorption coefficient will give similar results.

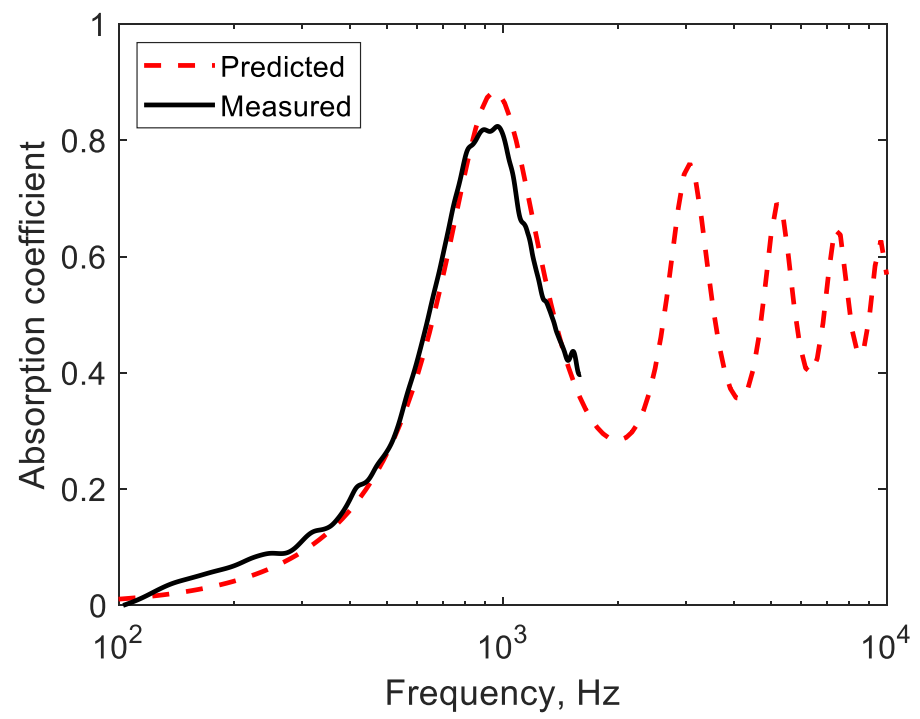

Figure 3 Absorption coefficient of porous rubber mat with thickness $46 \mathrm{~mm}$

A box-shaped train body, which was made of a dense foam and sealed with varnish, was suspended above the track by using wooden supports at its ends. The train body did not have bogies or wheels, and was not in contact with the track. It is therefore expected to introduce only geometrical effects. Although the bogies and wheels can be expected to modify the radiation of the track and the effectiveness of the absorptive treatment to some extent, the bogies only represent around $20 \%$ of the length of a carriage so the effect is expected to be small. The scale model train body is $2.5 \mathrm{~m}$ long with cross-sectional dimensions of $0.56 \mathrm{~m} \times$ $0.45 \mathrm{~m}$ (width $\times$ height). The train floor was $0.16 \mathrm{~m}$ above the top of the rail. The whole arrangement is shown in Figure 4.

Table 1 Characteristics used to represent porous rubber mat [20]

\begin{tabular}{|l|l|}
\hline Porosity & 0.31 \\
\hline Flow resistivity & $22650 \mathrm{Ns} / \mathrm{m}^{4}$ \\
\hline Tortuosity & 2.6 \\
\hline Viscous characteristic length & $0.2 \mathrm{~mm}$ \\
\hline Thermal characteristic length & $0.2 \mathrm{~mm}$ \\
\hline Young's modulus & $7.1 \times 10^{9} \mathrm{~N} / \mathrm{m}^{2}$ \\
\hline
\end{tabular}




\begin{tabular}{|l|l|}
\hline Poisson's ratio & 0.4 \\
\hline Density & $1300 \mathrm{~kg} / \mathrm{m}^{3}$ \\
\hline Loss factor & 0.1 \\
\hline
\end{tabular}

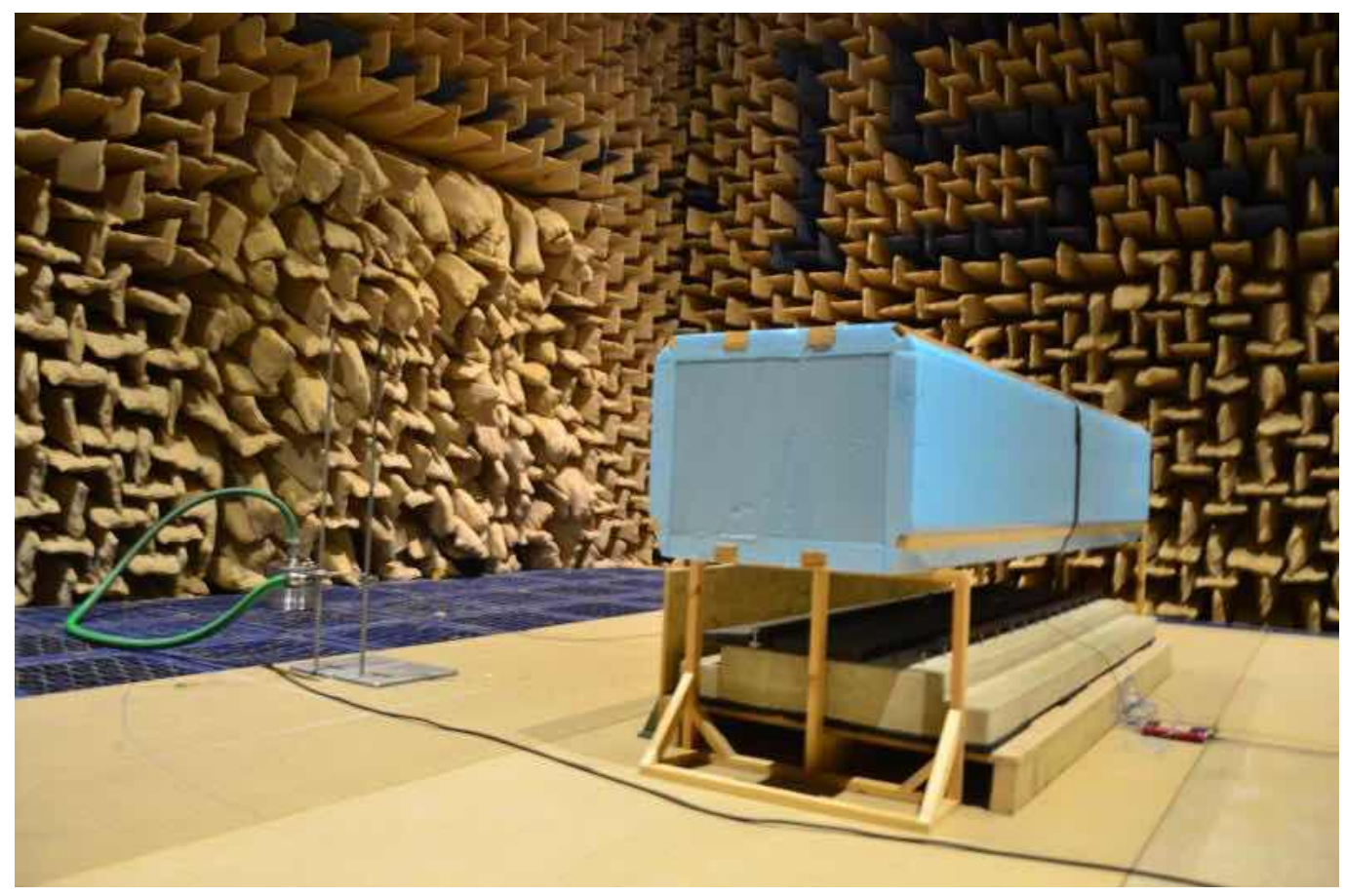

Figure 4 Experimental set-up including car body

\subsection{Measurement method}

It was foreseen that a direct method (using a shaker or impact hammer) would present some practical problems. A shaker is likely to radiate more noise than the rail itself as the scaled track is a relatively stiff structure. On the other hand, use of an impact hammer would affect the sound propagation because the person using it is in close proximity to the track. A reciprocal approach, therefore, has been used in the tests, which avoids these problems. This is shown schematically in Figure 5. According to the principle of vibro-acoustic reciprocity [19], the transfer function in the direct experiment (a) between a point force $F_{a}$ acting on a structure at point $A$ and the resulting sound pressure $p_{a}$ at a receiver $B$ is identical to the transfer function in the reciprocal experiment (b) between a volume velocity $Q_{b}$ of a point monopole located at the point $B$ and the resulting vibration velocity $v_{b}$ produced at original excitation point $A$ :

$$
\frac{p_{a}}{F_{a}}=\frac{v_{b}}{Q_{b}}
$$




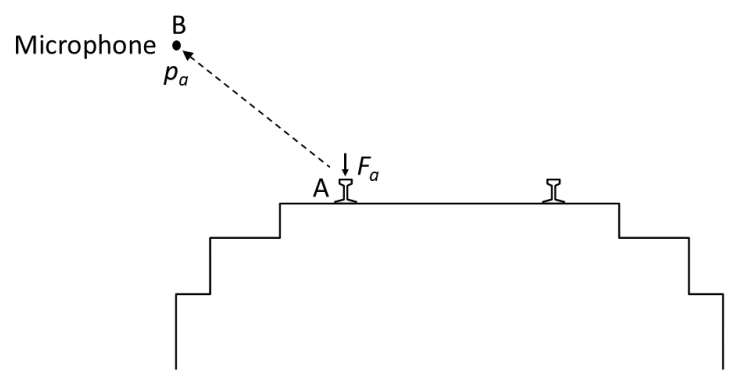

(a)

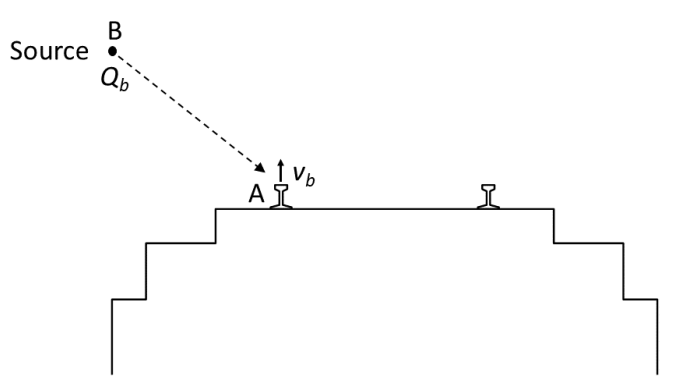

(b)

Figure 5 Principle of reciprocity used in the measurement. (a) Direct method; (b) reciprocal method

Thus, if $v_{b}$ and $Q_{b}$ are measured, the ratio of $p_{a}$ and $F_{a}$ can be determined. Equation (1) can also be expressed in terms of root-mean-square quantities. In the current experiments, the results are rescaled in terms of the mean-square velocity averaged over the length of the rail, $\left\langle v_{a}^{2}\right\rangle$ :

$$
\frac{p_{a}^{2}}{\left\langle v_{a}^{2}\right\rangle}=\frac{v_{b}^{2}}{Q_{b}^{2}} / \frac{\left\langle v_{a}^{2}\right\rangle}{F_{a}^{2}}
$$

where the denominator on the right-hand side is equal to the average of the squared transfer mobility of the rail, which was previously determined and shown in Figure 2(b).

The insertion loss of a particular measure can be determined from

$$
\mathrm{IL}=10 \log _{10} \frac{p_{1}^{2}}{\left\langle v_{1}^{2}\right\rangle}-10 \log _{10} \frac{p_{0}^{2}}{\left\langle v_{0}^{2}\right\rangle}
$$

where $p_{0}$ is the sound pressure at the receiver without the treatment, $p_{1}$ is the sound pressure with the treatment and $v_{0}$ and $v_{1}$ are the corresponding rail velocities. This is equal to the sound pressure level difference for a constant rail velocity.

A monopole-like source consisting of a driver connected to a stiff hose has been used to excite the system. Its directivity was first checked to ensure that it acts approximately as a monopole and its volume velocity $Q_{b}$ has been determined. In the measurements a reference microphone was installed at a distance of $11 \mathrm{~cm}$ from the nozzle to ensure that the source strength remained constant.

The source positions are shown in Figure 6. They are located at a distance of $1.5 \mathrm{~m}$ from the centreline of the track, which is equivalent to $7.5 \mathrm{~m}$ at full scale corresponding to the standard positions according to ISO 3095 [21]. Four different source heights are considered: $0 \mathrm{~m}, 0.24$ 
$\mathrm{m}, 0.5 \mathrm{~m}$ and $0.7 \mathrm{~m}$ above the top of the rail, which are equivalent to $0 \mathrm{~m}, 1.2 \mathrm{~m}, 2.5 \mathrm{~m}$ and 3.5 $\mathrm{m}$ at full scale. For each height the source was placed at 11 positions parallel to the track separated by an interval of $0.2 \mathrm{~m}$.

A white noise signal was used to excite the source. The acceleration of the rail head in both vertical and lateral directions was measured at the centre of the track. This is used to determine the velocity $v_{b}$ in Equation (2). The results are usable above $500 \mathrm{~Hz}(100 \mathrm{~Hz}$ at full scale) where the signal-to-noise ratio of the rail vibration was at least $7 \mathrm{~dB}$.

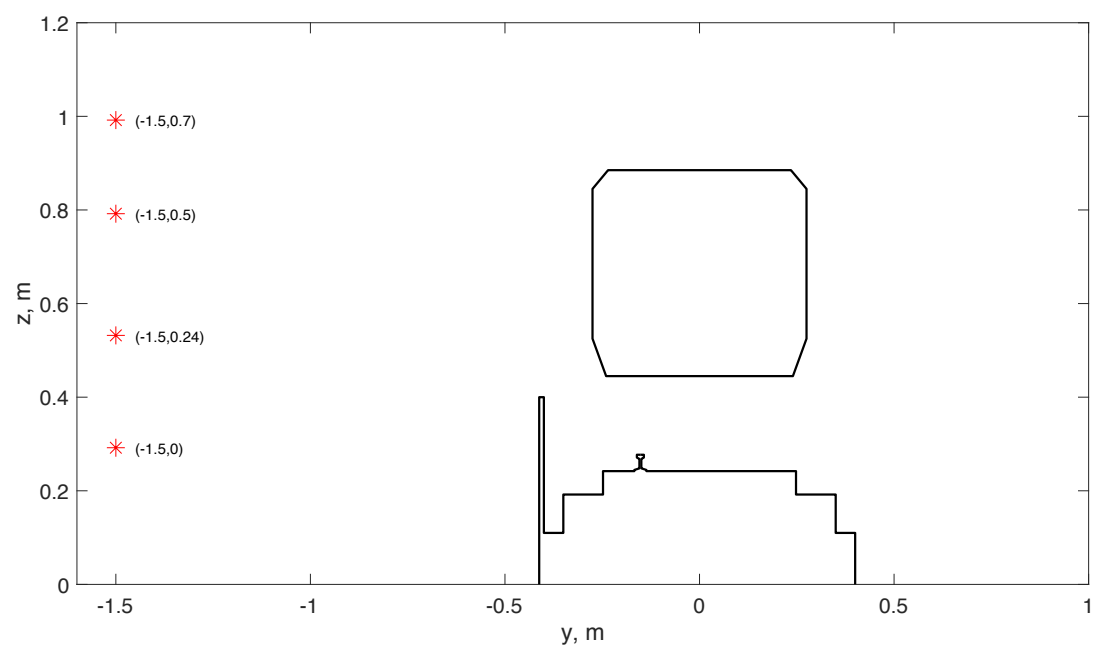

Figure 6 Equivalent receiver positions (positions of the sound source in the measurement)

\section{Numerical modelling of the measurement set-up}

For comparison with the measurements numerical models corresponding to the various configurations have been created, as shown in Figure 7. Two-dimensional (2D) boundary element models are used to represent the untreated track and the situation with the barrier. A 2D approach is acceptable for the rail radiation in the frequency region above the cut-on frequency of propagating waves [22]. Above this cut-on frequency of waves in the rail, the sound is radiated from the rail at an angle that is close to normal to its axis and a twodimensional model is appropriate. The ground is assumed to be rigid and is modelled by using a half-space formulation in the boundary element model. Where the car body is also included in the model it is represented using boundary elements and is assumed to be rigid. For the configurations including the porous material, a coupled finite element and boundary element model is used, including poro-elastic elements to represent the porous rubber material [20]. The parameters used to represent this material are listed in Table 1. The cases with a double layer of porous material are not considered in the simulations due to restrictions on the model 
size. Models with different element sizes are used for low and high frequency ranges, in each case ensuring at least six nodes per wavelength; the models shown in Figure 7 are the low frequency ones.

Only a single rail is included in the model. In all cases a unit velocity is assigned to the rail in either the vertical or lateral direction. In reality, at each fastener the rail is attached to the fasteners over its whole base so that its bottom surface does not radiate sound. Between the fasteners it is suspended $15 \mathrm{~mm}$ above the slab. These two geometrical conditions lead to different radiation efficiencies at low frequency [22]. Therefore, the calculations are performed for both of these conditions and the results are combined according to the procedure developed and validated in [23].

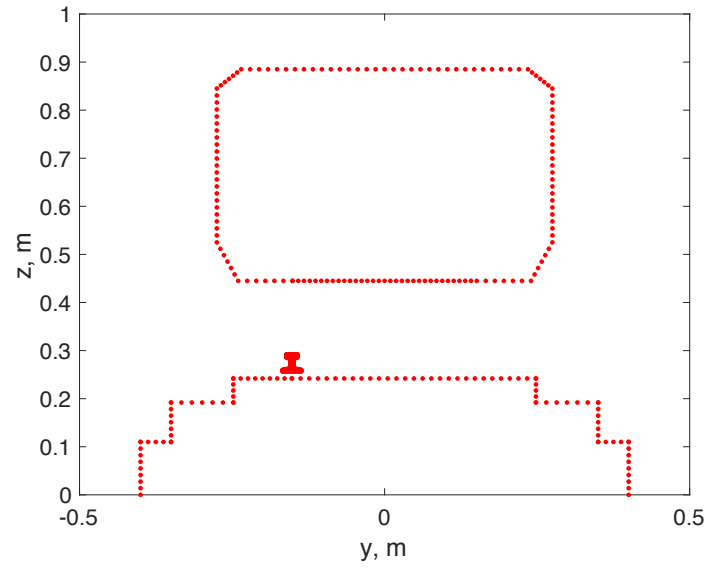

(a)

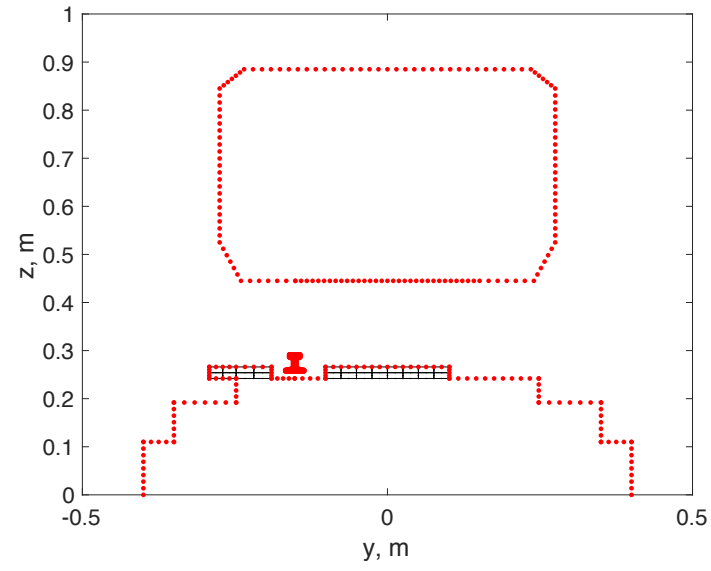

(b)

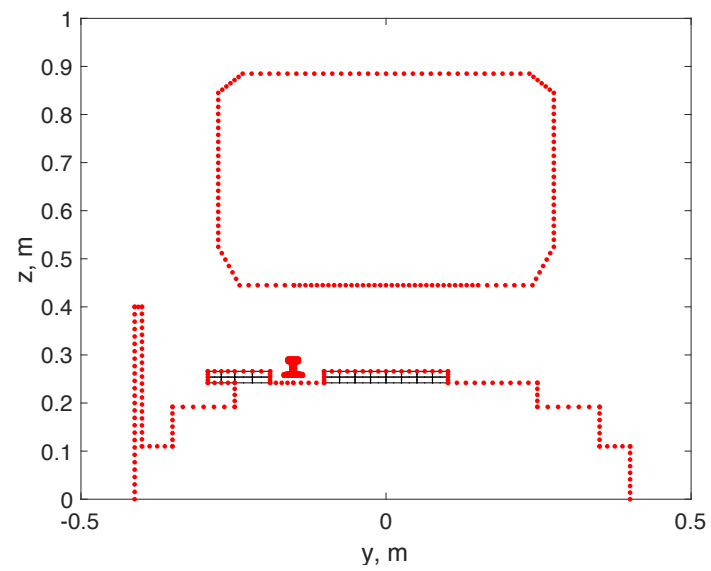

(c)

Figure 7 Boundary element (and finite element) mesh of the slab track with vehicle used for different situations. (a) Slab track without treatment; (b) with absorptive treatment (single layer); (c) with absorptive treatment and barrier 


\section{Results and discussion}

\subsection{Sound pressure results}

Figure 8(a) shows examples of the measured ratio $p_{a}^{2} /\left\langle v_{a}^{2}\right\rangle$ obtained according to Equation (2). These are for vertical rail vibration in the presence of the car body. They have been averaged over the 11 receiver positions for the height of $0.24 \mathrm{~m}$. The corresponding predicted results are shown in Figure 8(b). These are the sound pressure spectra at the receiver position at a height of $0.24 \mathrm{~m}$ for a unit velocity on the rail. In both figures the results are plotted against full scale frequencies, which means that the frequencies from the measurements and numerical models have been divided by the scale factor 5 . The measured results below $160 \mathrm{~Hz}(800 \mathrm{~Hz}$ in the scale model) are omitted as they may be contaminated by background noise on the accelerometer during the reciprocal measurements. The measurements and predictions show similar trends although there are some differences of detail. Below $250 \mathrm{~Hz}$ the predictions are consistently lower than the measurements. The reason for this is unclear, but in this frequency range the difference between the results with and without the treatments are close to 0 in both measurements and predictions.

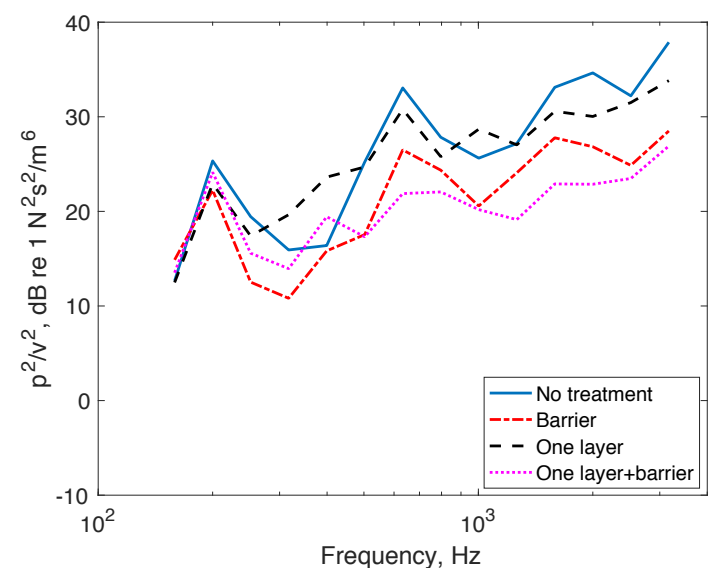

(a)

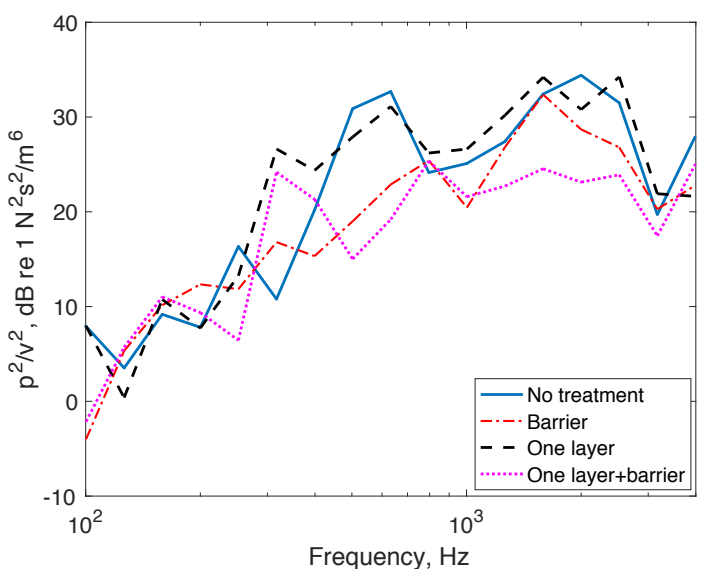

(b)

Figure 8 Comparison of numerical predictions and measurements in terms of $10 \log _{10}\left(p^{2} / v^{2}\right)$ for vertical motion of the slab track with car body for the receiver position at $0.24 \mathrm{~m}$ above the rail head. (a) Measurements; (b) predictions

\subsection{Insertion loss results}

The measured results for the four source positions are compared in the form of insertion losses in Figure 9 for vertical rail vibration. Results are shown for the case when the car body was not present in Figure 9(a,c,e) and when it was included in Figure 9(b,d,f). These results are again plotted against full scale frequencies. 


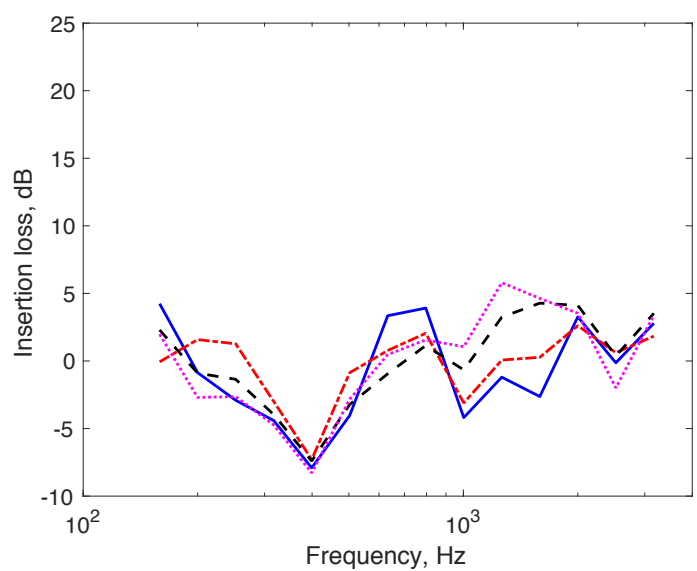

(a)

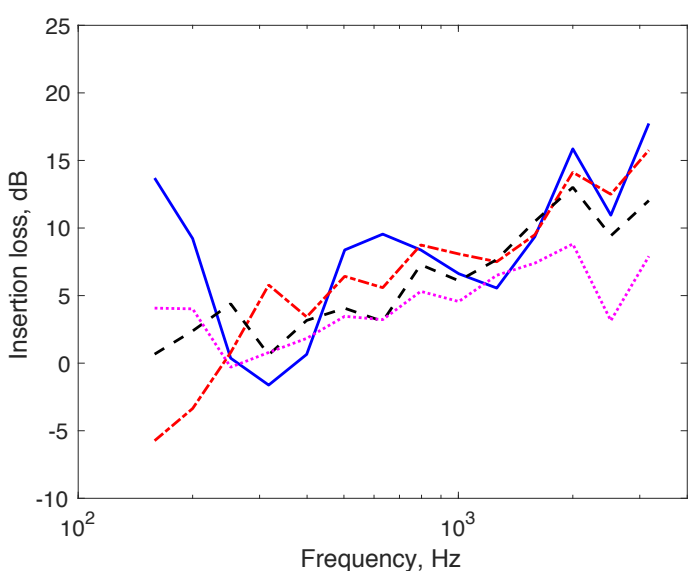

(c)

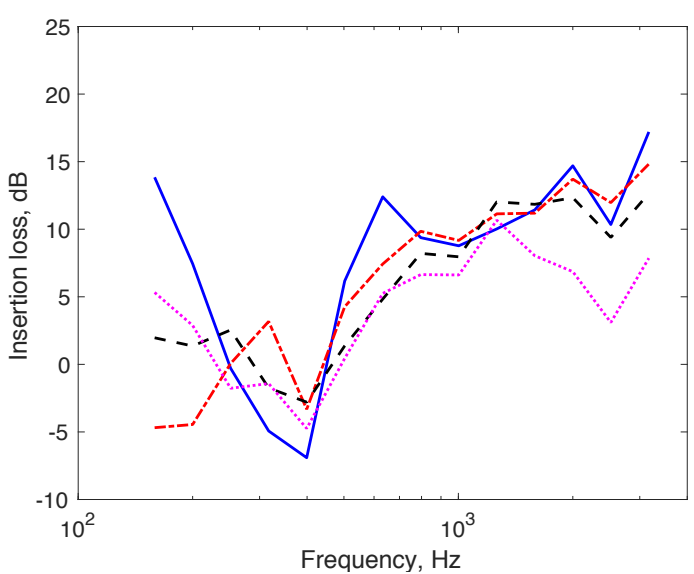

(e)

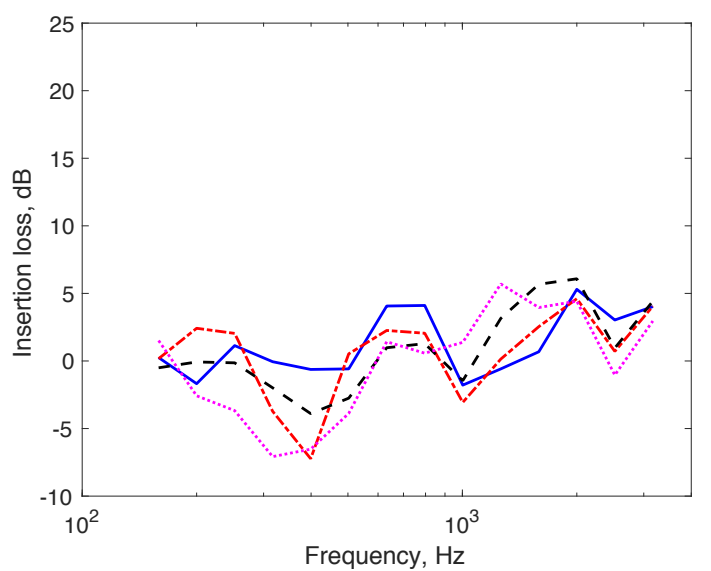

(b)

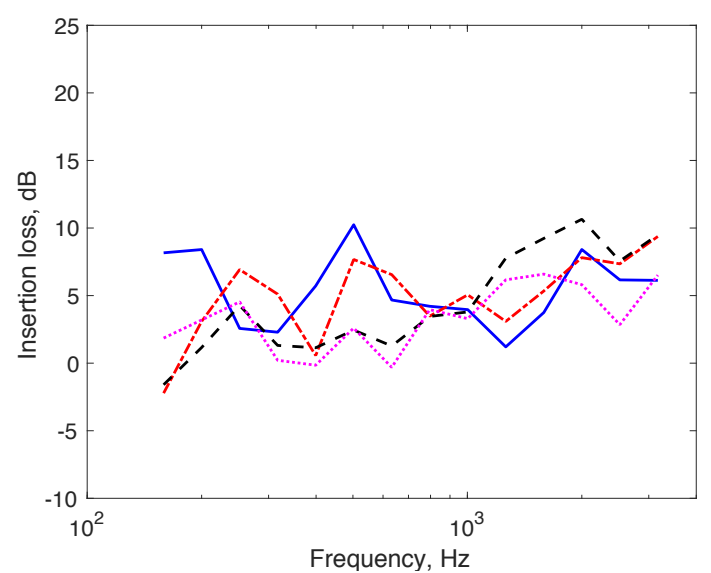

(d)

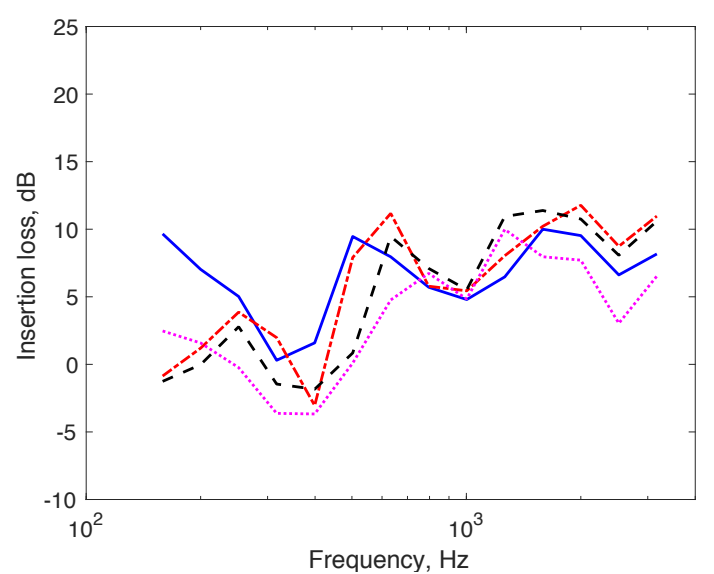

(f)

Figure 9 Measured insertion loss of different measures for vertical rail vibration at different receiver heights above the rail. —: $0 \mathrm{~m} ;-\cdot-\cdot 0.24 \mathrm{~m} ;---: 0.5 \mathrm{~m} ; \cdots \cdots . .0 .7 \mathrm{~m}$. (a,b) With single layer absorptive treatment; (c,d) with barrier; (e,f) with both. (a,c,e): without car body; (b,d,f): with car body. 
In all the results the barrier is more effective than the rubber panel and its effectiveness is greater at the lower receiver positions than at the higher ones. In contrast, the effect of the absorptive panel is not strongly dependent on the source height. The absorptive treatment gives a negative insertion loss at low frequencies, especially around $400 \mathrm{~Hz}$ (Figure 9(a)). In this region the rail radiation forms a line quadrupole $[22,23]$ due to reflection in the slab. The presence of the absorptive layer reduces the strength of the image source leading to an increase in the radiation. A similar dip in the insertion loss is seen in Figure 9(e). By introducing the car body, Figure $9(\mathrm{~b}, \mathrm{~d}, \mathrm{f})$, the effectiveness of the barrier is reduced considerably, especially at high frequencies, whereas the absorptive panel becomes slightly more effective. The combination of the two measures leads to larger insertion losses than either separately, especially at high frequency, as shown in Figure 9(e,f).

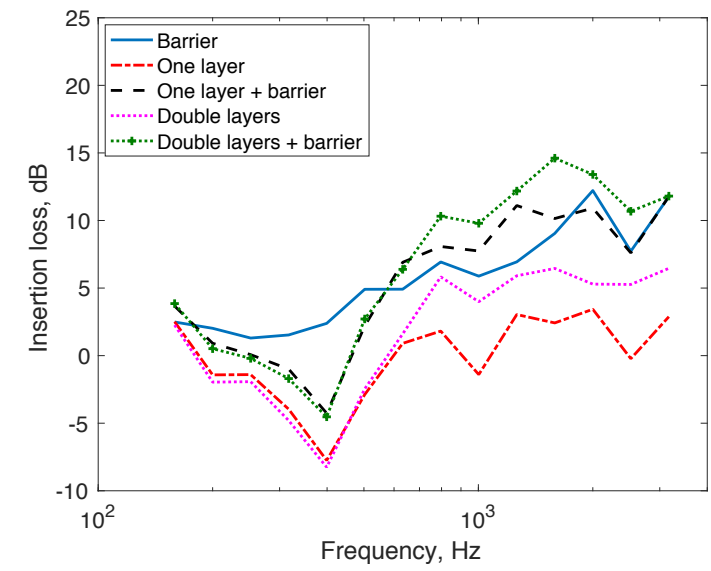

(a)

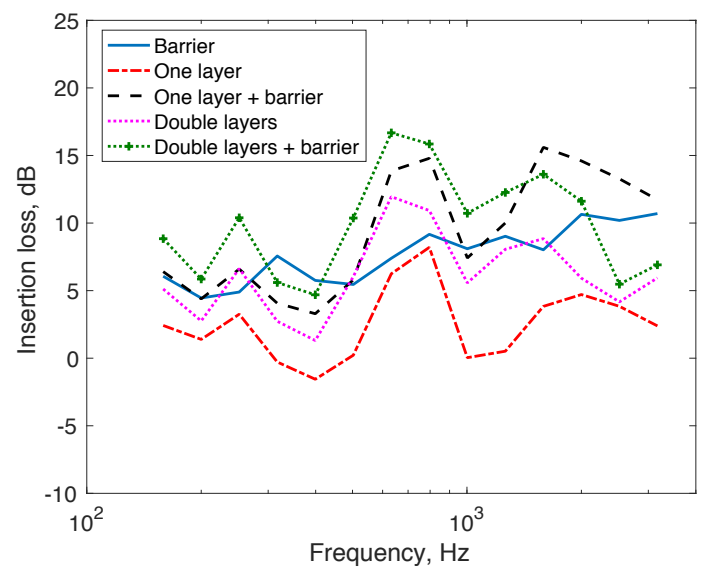

(c)

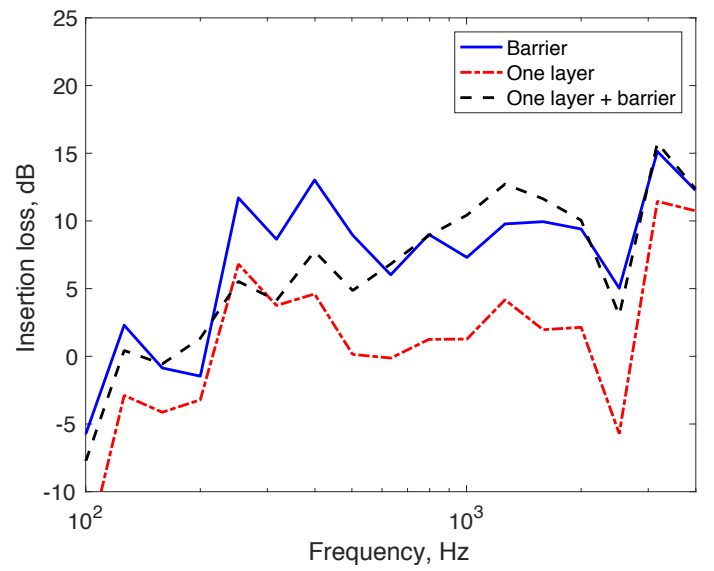

(b)

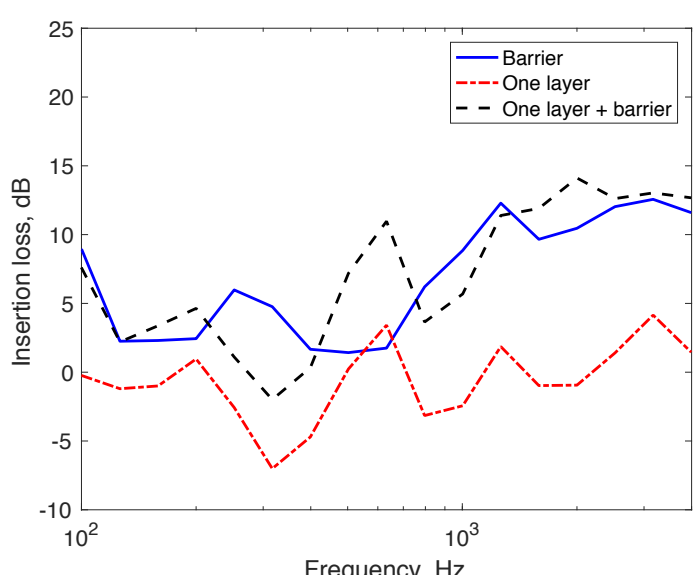

(d)

Figure 10 Average insertion loss without the car body. (a) Measurement, vertical rail vibration; (b) prediction, vertical rail vibration; (c) measurement, lateral rail vibration; (d) prediction, lateral rail vibration 
An average spectrum for each configuration is calculated as the average of $p^{2} /<v^{2}>$ over the four receiver heights and 11 locations. These results are then used to determine an average insertion loss spectrum for each configuration, which is calculated as the level difference between these average results with and without the treatment. These are presented in Figure 10 for cases without the car body present and the corresponding results with the car body present are shown in Figure 11. In each case both measured and predicted results are shown for both vertical and lateral vibration of the rail. Similar trends are seen in the measured and predicted results despite some differences between the results.

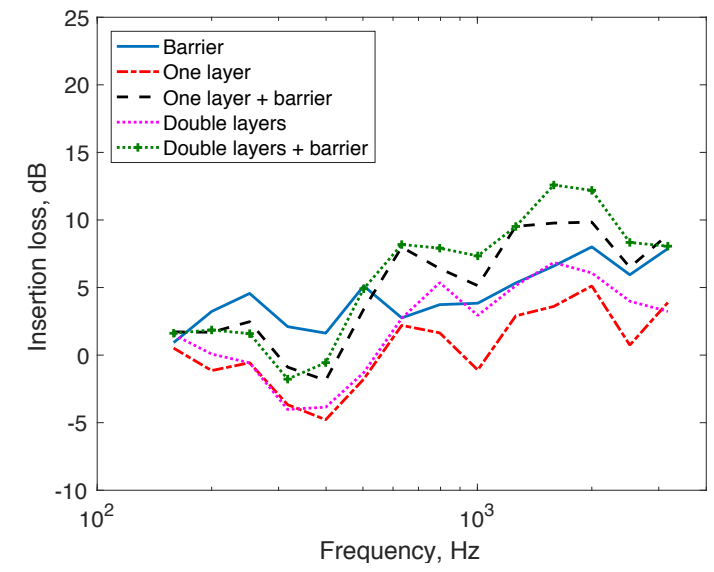

(a)

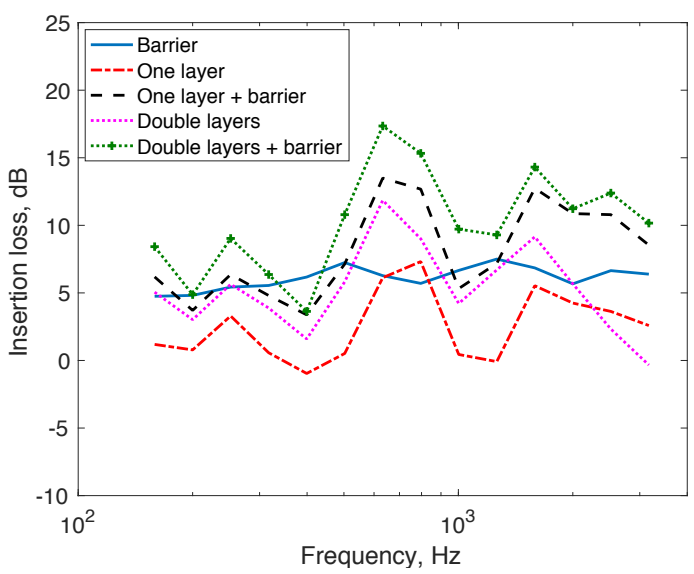

(c)

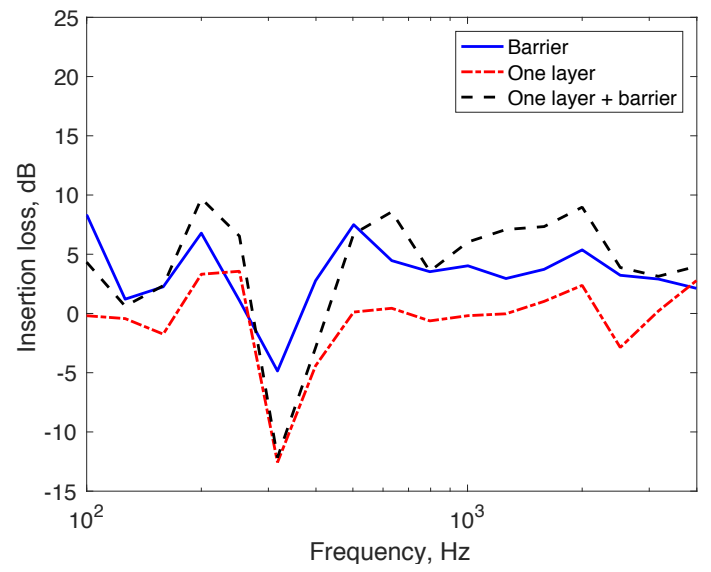

(b)

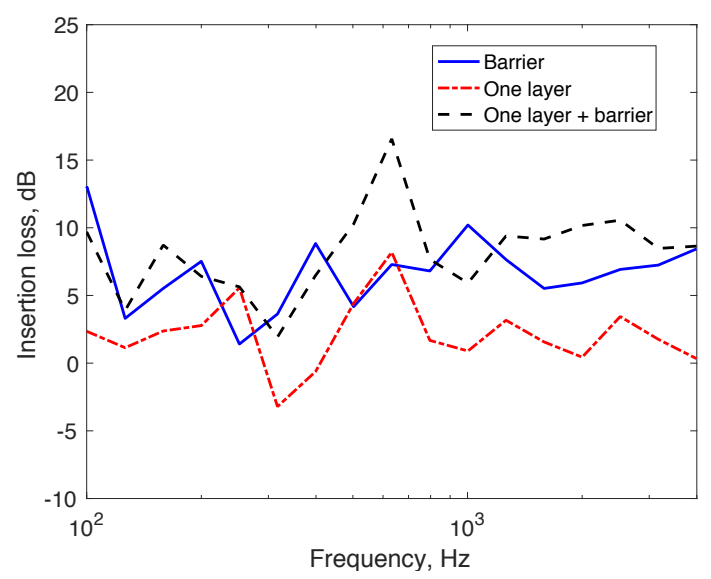

(d)

Figure 11 Average insertion loss with the car body. (a) Measurement, vertical rail vibration; (b) prediction, vertical rail vibration; (c) measurement, lateral rail vibration; (d) prediction, lateral rail vibration

From both measured and predicted results, the insertion loss for the single layer of absorptive material without the car body is close to $0 \mathrm{~dB}$ over much of the frequency range. It is improved 
a little at higher frequencies for the vertical rail vibration when the car body is present, which suggests that the absorptive layer reduces reflections between the car body and the track. Using a double layer of absorptive material gives an improved insertion loss for the vertical direction above $630 \mathrm{~Hz}$ and for the lateral direction at all frequencies.

As would be expected, the effectiveness of the noise barrier increases with increasing frequency, with an average insertion loss of $10 \mathrm{~dB}$ by $2 \mathrm{kHz}$. However, when the car body is present the high frequency performance is reduced due to the reflections from the underside of the car body. The combined effect of the barrier and the absorptive treatment is greater than either of the measures alone for frequencies above $500 \mathrm{~Hz}$, but at low frequencies the effect of the barrier can be reduced by the presence of the absorptive treatment. In most cases for frequencies above $500 \mathrm{~Hz}$, it has been found that the insertion loss of the barrier and the absorptive treatment together is almost the same as the sum of the effects of the two treatments applied separately.

\section{Estimates of effects on train pass-by noise}

To summarise these results in terms of single number attenuations, the measured insertion loss spectra have been combined with estimates of the rolling noise from a train pass-by. The TWINS model [24] has been used to predict the rolling noise from a slab track using the same parameters as given in [2]. The roughness spectrum used is the limit spectrum from ISO 3095:2013 [25] which is typical of a low amplitude roughness spectrum. Three representative train speeds are used, 80, 160 and $300 \mathrm{~km} / \mathrm{h}$; other sources such as aerodynamic noise are neglected.

Table 2 lists the A-weighted noise levels of each component for the situation with no treatment; these are given at the receivers located at $7.5 \mathrm{~m}$ from the track centre and 1.2 or $3.5 \mathrm{~m}$ above the rail. In this initial situation it can be seen that the rail is the dominant source in each case; the wheel produces between 6 and $9 \mathrm{~dB}$ less noise than the rail, indicating that most of the noise reduction predicted for the rail will also be reflected in the total noise. 
Table 2 Predicted A-weighted noise levels in $\mathrm{dB}$ for untreated track

\begin{tabular}{|l|c|c|c|c|c|c|}
\hline \multicolumn{1}{|c|}{ Train speed } & \multicolumn{2}{|c|}{$80 \mathrm{~km} / \mathrm{h}$} & \multicolumn{2}{c|}{$160 \mathrm{~km} / \mathrm{h}$} & \multicolumn{2}{c|}{$300 \mathrm{~km} / \mathrm{h}$} \\
\hline Receiver height & $1.2 \mathrm{~m}$ & $3.5 \mathrm{~m}$ & $1.2 \mathrm{~m}$ & $3.5 \mathrm{~m}$ & $1.2 \mathrm{~m}$ & $3.5 \mathrm{~m}$ \\
\hline Rail noise (vertical) & 78.1 & 78.1 & 86.1 & 86.1 & 92.2 & 92.1 \\
\hline Rail noise (lateral) & 75.9 & 74.0 & 83.7 & 82.1 & 90.0 & 88.6 \\
\hline Wheel noise & 71.3 & 70.2 & 79.7 & 78.9 & 88.4 & 87.7 \\
\hline Total & 80.7 & 80.0 & 88.7 & 88.1 & 95.2 & 94.7 \\
\hline
\end{tabular}

The noise spectra from the vertical and lateral motion of the rail are calculated separately and the corresponding insertion loss spectra are subtracted from these results. The spectra are then summed to give the overall A-weighted noise levels in each case and used to determine the attenuation of noise due to the various mitigation measures. The wheel noise will also be affected to some extent by these treatments, especially the barrier, but for simplicity this effect is not considered.

The reductions in noise from the rail for the various mitigation measures are shown in Table 3 for each speed and receiver height. These results are based on the insertion losses measured without the car body present. The thinner absorptive panel gives a negligible effect at $1.2 \mathrm{~m}$ height and a small negative effect at $3.5 \mathrm{~m}$ whereas the thicker absorptive panel is on average $1.4 \mathrm{~dB}$ more effective than the thinner one. The barrier is more effective at the lower receiver position than at the upper position. Including the absorptive treatment does not make the barrier any more effective, which is consistent with the fact that its insertion loss is negligible when considered alone. The effectiveness of all these treatments increases, by between roughly 0.5 and $1.5 \mathrm{~dB}$, as speed is increased from 80 to $300 \mathrm{~km} / \mathrm{h}$. This is a consequence of the greater high frequency content at higher speeds and higher insertion losses occurring at high frequencies.

These results are modified in the presence of the car body, as shown in Table 4. The noise reduction for the thicker absorptive panel increases to an average of $2.8 \mathrm{~dB}$ at $1.2 \mathrm{~m}$ height but at $3.5 \mathrm{~m}$ height the absorptive treatments give similar results to those obtained without the car body. The barrier by itself is $1-2 \mathrm{~dB}$ less effective in the presence of the car body and its effectiveness no longer increases with train speed. Conversely, the barrier with the absorptive treatment becomes more effective in the presence of the car body, especially at the lower 
receiver height, where an average reduction of $8.2 \mathrm{~dB}$ is achieved with the double layer. However, at $3.5 \mathrm{~m}$ height the average attenuation is only $4.6 \mathrm{~dB}$, which is only a small improvement over the result without the car body. The effectiveness of this combined treatment increases with increasing train speed at both receivers.

If account is also taken of the wheel noise, by assuming as a worst case that it is subject to negligible attenuation, it is found that the total noise is reduced by an average of $5.6 \mathrm{~dB}$ at 1.2 $\mathrm{m}$ and $3.5 \mathrm{~dB}$ at $3.5 \mathrm{~m}$ for the barrier with the double thickness absorptive treatment. In reality, the barrier will also attenuate the wheel noise to some extent.

Table 3 Reductions in A-weighted noise level from the rail in $\mathrm{dB}$ due to various measures (without car body)

\begin{tabular}{|l|c|c|c|c|c|c|}
\hline \multicolumn{1}{|r|}{ Train speed } & \multicolumn{2}{|c|}{$80 \mathrm{~km} / \mathrm{h}$} & \multicolumn{2}{c|}{$160 \mathrm{~km} / \mathrm{h}$} & \multicolumn{2}{c|}{$300 \mathrm{~km} / \mathrm{h}$} \\
\hline \multicolumn{1}{|c|}{ Receiver height } & $1.2 \mathrm{~m}$ & $3.5 \mathrm{~m}$ & $1.2 \mathrm{~m}$ & $3.5 \mathrm{~m}$ & $1.2 \mathrm{~m}$ & $3.5 \mathrm{~m}$ \\
\hline Absorptive panel & -0.5 & -1.2 & 0.0 & -0.6 & 0.3 & -0.2 \\
\hline Double absorptive panel & 0.7 & 0.0 & 1.4 & 0.8 & 1.9 & 1.3 \\
\hline Barrier & 7.1 & 3.8 & 7.4 & 4.0 & 7.6 & 4.2 \\
\hline Barrier with absorptive panel & 5.7 & 2.8 & 6.4 & 3.5 & 7.0 & 3.9 \\
\hline Barrier with double panel & 5.9 & 3.2 & 6.7 & 4.0 & 7.3 & 4.5 \\
\hline
\end{tabular}

Table 4 Reductions in A-weighted noise level from the rail in $\mathrm{dB}$ due to various measures (with car body)

\begin{tabular}{|l|c|c|c|c|c|c|}
\hline \multicolumn{1}{|r|}{ Train speed } & \multicolumn{2}{|c|}{$80 \mathrm{~km} / \mathrm{h}$} & \multicolumn{2}{c|}{$160 \mathrm{~km} / \mathrm{h}$} & \multicolumn{2}{c|}{$300 \mathrm{~km} / \mathrm{h}$} \\
\hline \multicolumn{1}{|c|}{ Receiver height } & $1.2 \mathrm{~m}$ & $3.5 \mathrm{~m}$ & $1.2 \mathrm{~m}$ & $3.5 \mathrm{~m}$ & $1.2 \mathrm{~m}$ & $3.5 \mathrm{~m}$ \\
\hline Absorptive panel & -0.1 & -1.3 & 0.4 & -0.8 & 0.8 & -0.4 \\
\hline Double absorptive panel & 2.2 & 0.0 & 2.8 & 0.6 & 3.3 & 1.1 \\
\hline Barrier & 6.0 & 1.9 & 5.9 & 2.1 & 5.8 & 2.4 \\
\hline Barrier with absorptive panel & 6.3 & 2.5 & 6.8 & 3.1 & 7.2 & 3.6 \\
\hline Barrier with double panel & 7.7 & 3.9 & 8.3 & 4.6 & 8.7 & 5.2 \\
\hline
\end{tabular}

Table 5 shows the noise reductions averaged over the three speeds at the $1.2 \mathrm{~m}$ receiver height and Table 6 shows the corresponding results for the $3.5 \mathrm{~m}$ height. As well as the overall reduction in rail noise, these tables show the reductions in the vertical and lateral components of the rail noise. 
For the vertical direction, it was seen in Figure 10(a) and Figure 11(a) that the absorptive treatments give an amplification at low frequency and an attenuation at high frequency. The overall effect therefore depends on the shape of the noise spectrum. The thicker treatment has a greater high frequency attenuation and so, in overall terms, although the insertion loss of the single layer is negative, that of the double layer is zero or positive. In all cases the noise reduction for the lateral component is greater than that for the vertical component and the attenuation for the $1.2 \mathrm{~m}$ receiver height is greater than that for the $3.5 \mathrm{~m}$ height. The thicker absorptive panel gives an average reduction at the $1.2 \mathrm{~m}$ receiver of about $6 \mathrm{~dB}$ for the lateral component, with or without the car body. For the barrier in combination with the thicker panel, the lateral component is reduced by $12 \mathrm{~dB}$. At the $3.5 \mathrm{~m}$ height the corresponding attenuations are smaller, but still considerably better than the results for the vertical direction. Clearly, if the lateral component is neglected in determining the effectiveness of the treatments their insertion loss would be underestimated.

Table 5 Reductions in A-weighted noise level from the rail in $\mathrm{dB}$ due to various measures (average over three speeds, at $1.2 \mathrm{~m}$ receiver height)

\begin{tabular}{|l|c|c|c|c|c|c|}
\hline & \multicolumn{2}{|c|}{ Rail total } & \multicolumn{2}{c|}{ Rail vertical } & \multicolumn{2}{c|}{ Rail lateral } \\
\hline & $\begin{array}{c}\text { Without } \\
\text { carbody }\end{array}$ & $\begin{array}{c}\text { With } \\
\text { carbody }\end{array}$ & $\begin{array}{c}\text { Without } \\
\text { carbody }\end{array}$ & $\begin{array}{c}\text { With } \\
\text { carbody }\end{array}$ & $\begin{array}{c}\text { Without } \\
\text { carbody }\end{array}$ & $\begin{array}{c}\text { With } \\
\text { carbody }\end{array}$ \\
\hline Absorptive panel & -0.1 & 0.4 & -0.9 & -0.2 & 1.8 & 1.6 \\
\hline Double absorptive panel & 1.3 & 2.8 & -0.1 & 1.7 & 6.1 & 5.8 \\
\hline Barrier & 7.4 & 5.9 & 6.6 & 5.1 & 9.0 & 7.5 \\
\hline Barrier with absorptive panel & 6.4 & 6.8 & 5.1 & 5.8 & 9.9 & 9.2 \\
\hline Barrier with double panel & 6.6 & 8.2 & 5.1 & 7.0 & 11.9 & 11.5 \\
\hline
\end{tabular}

Table 6 Reductions in A-weighted noise level from the rail in $\mathrm{dB}$ due to various measures (average over three speeds, at $3.5 \mathrm{~m}$ receiver height)

\begin{tabular}{|l|c|c|c|c|c|c|}
\hline & \multicolumn{2}{|c|}{ Rail total } & \multicolumn{2}{c|}{ Rail vertical } & \multicolumn{2}{c|}{ Rail lateral } \\
\hline & $\begin{array}{c}\text { Without } \\
\text { carbody }\end{array}$ & $\begin{array}{c}\text { With } \\
\text { carbody }\end{array}$ & $\begin{array}{c}\text { Without } \\
\text { carbody }\end{array}$ & $\begin{array}{c}\text { With } \\
\text { carbody }\end{array}$ & $\begin{array}{c}\text { Without } \\
\text { carbody }\end{array}$ & $\begin{array}{c}\text { With } \\
\text { carbody }\end{array}$ \\
\hline Absorptive panel & -0.7 & -0.8 & -1.0 & -1.1 & 0.1 & 0.0 \\
\hline Double absorptive panel & 0.7 & 0.6 & -0.2 & -0.1 & 4.0 & 2.7 \\
\hline Barrier & 4.0 & 2.1 & 3.9 & 1.5 & 4.2 & 4.1 \\
\hline
\end{tabular}




\begin{tabular}{|l|l|l|l|l|l|l|}
\hline Barrier with absorptive panel & 3.4 & 3.1 & 3.0 & 2.8 & 4.5 & 3.7 \\
\hline Barrier with double panel & 3.9 & 4.6 & 3.1 & 4.1 & 7.0 & 5.9 \\
\hline
\end{tabular}

Treatments applied in practice on a track could differ in a number of ways from those considered in these reduced scale experiments. In particular, the absorptive material used in the scale model has a peak in its absorption coefficient at around $1 \mathrm{kHz}(200 \mathrm{~Hz}$ at full scale) and a dip at $2 \mathrm{kHz}$ (400 Hz full scale). At higher frequencies its average absorption coefficient is only around 0.5 . Materials typically applied in track such as porous concrete are likely to be more effective, with high absorption coefficients over a wider frequency range $[15,16]$. The barrier corresponds to one at full scale with a height of $0.55 \mathrm{~m}$ above the top of the rail, located $2 \mathrm{~m}$ away from the centre of the track. Such a design is realistic for a very close barrier and shows that although the noise at the standard receiver location at $1.2 \mathrm{~m}$ height can be attenuated, the effect at a higher receiver is smaller. In practice, an absorptive barrier would be expected to be more effective. Although the car body is simplified, it is clear from these results that it is important to include the presence of the train body in any assessment of the effects of acoustic treatments.

\section{Conclusions}

Scale model experiments and numerical simulations have been used to study combinations of absorptive treatments and a low height close barrier applied to a slab track. The insertion losses obtained from these results have been combined with predicted train pass-by spectra at receiver positions $7.5 \mathrm{~m}$ from the track centre to determine the likely overall noise reductions. These have been determined for a typical slab track and for three representative train speeds. The numerical simulations gave results that are broadly consistent with the measurements.

The absorptive treatment alone was found to have only a small effect on the radiated noise from the track; this was increased a little when the measurements were made in the presence of the train body giving an overall noise reduction of up to $2-3 \mathrm{~dB}$ at the $1.2 \mathrm{~m}$ microphone height for the thicker treatment, which is consistent with results in the literature [11-18]. This suggests that the absorptive layer controls reflections between the car body and the track to some extent. The attenuation at the $3.5 \mathrm{~m}$ microphone height was found to be much smaller and a thinner absorptive layer had a negligible effect at this position. The effect of the 
absorptive treatment on the noise radiated by the lateral vibration of the rail is significantly greater than that for the vertical vibration, especially at the $1.2 \mathrm{~m}$ receiver height. For practical application, a material with a higher absorption coefficient would give improved performance.

The noise barrier, with a height equivalent to $0.55 \mathrm{~m}$ above the top of the rail at full scale, was also found to be more effective at the lower receiver position (average reduction $7.4 \mathrm{~dB}$ ) than at the upper position $(4.0 \mathrm{~dB})$. However, these results were reduced by $1-2 \mathrm{~dB}$ when the train body was included. On the other hand, the noise barrier in combination with the absorptive treatment was more effective in the presence of the car body than without, giving an average reduction of $8.2 \mathrm{~dB}$ in the rail noise at the receiver height of $1.2 \mathrm{~m}$. From these results it is clear that it is important to include the presence of the train in any assessment of the effects of acoustic treatments.

\section{Acknowledgements}

The work described here has been supported by the EPSRC under the programme grant EP/M025276/1, 'The science and analytical tools to design long life, low noise railway track systems (Track to the Future)' and was also supported by the Korean Railroad Research Institute (KRRI) though a grant (15RTRP-B072484-03) from Railroad Technology Research Program funded by Ministry of Land, Infrastructure and Transport of the Korean government.

\section{References}

[1] C. Esveld, Modern railway track. 2nd ed. MRT productions: Zaltbommel, 2001.

[2] X. Zhang, H. Jeong, D.J. Thompson, G. Squicciarini, The noise radiated by ballasted and slab tracks, Applied Acoustics, 151 (2019) 193-205.

[3] D.J. Thompson, Railway Noise and Vibration Mechanisms, Modelling and Means of Control, Elsevier, Oxford, 2009.

[4] D.J. Thompson, X. Zhang, G. Squicciarini, Effect of ground conditions and microphone position on railway noise measurement results, Proc. $13^{\text {th }}$ International Workshop on Railway Noise, Ghent, Belgium, September 2019. 
[5] D.J. Thompson, P-E. Gautier, 2006, A review of research into wheel/rail rolling noise reduction. Proceedings of the Institution of Mechanical Engineers, Part F (Journal of Rail and Rapid Transit), 220 (2006), F4, 385-408.

[6] D.J. Thompson, C.J.C. Jones, T.P. Waters, D. Farrington, 2007, A tuned damping device for reducing noise from railway track. Applied Acoustics, 68 (2007), 43-57.

[7] B. Asmussen, D. Stiebel, P. Kitson, D. Farrington, D. Benton, Reducing the noise emission by increasing the damping of the rail: results of a field test. In: B. SchulteWerning et al. (eds) Notes on Numerical Fluid Mechanics and Multidisciplinary Design, 99 (2008), 229-235.

[8] M. Beier, T. Lölgen, M. Starnberg, Innovative measures for reducing noise radiation from track. In J.C.O. Nielsen et al. (eds) Notes on Numerical Fluid Mechanics and Multidisciplinary Design, 126 (2015), 173-180.

[9] S. van Lier. The vibro-acoustic modelling of slab track with embedded rails. Journal of Sound and Vibration, 231(3), 805-817, 2000.

[10] M.H.A. Janssens, Low noise slab-track design: acoustic development and final tests. In Proceedings of the Sixth International Congress on Sound and vibration, Lyngby, Denmark, 1999, pp. 2643-2652.

[11] G. Hauck, W. Weissenberger, J. Scheuren, E. Lange, Untersuchungen zur Verringerung der Schallabstrahlung von 'Feste Fahrbahnen' durch absorbierende Beläge (Research into reduction of noise radiation from ballastless tracks through absorbing layers). Eisenbahntechnische Rundschau, 1995, 44, 559-565.

[12] R.J. Diehl, R. Nowack and G. Hölzl. Solutions for acoustical problems with ballastless track. Journal of Sound and Vibration, 231(3), 899-906, 2000.

[13] C. M. Weber, D. Sburlati. Source noise control to mitigate airborne noise at high rise developments - Epping to Chatswood Rail Link. Proceedings of 20th International Congress on Acoustics, ICA 2010, Sydney, Australia.

[14] K. Vogiatzis, P. Vanhonacker. Noise reduction in urban LRT networks by combining track based solutions, Science of the Total Environment, 568 (2016), 1344-1354.

[15] C. Zhao, P. Wang, L. Wang, D. Liu. Reducing railway noise with porous soundabsorbing concrete slabs. Advances in Materials Science and Engineering, 206549, 2014.

[16] J. Kim, K. Kim, The properties of noise absorbing blocks and their applications for railway, in: Inter-Noise and Noise-Con Congress and Conference Proceedings, Institute of Noise Control Engineering, 2011, pp. 4708-4713. 
[17] D. Shin, Y. Park, Analysis of noise reduction effect of concrete slab by the sound absorption block in urban railway, Vol. 1, The Korean Society for Railway, 2017, pp. 321-322.

[18] S. Byrne, An assessment of the effectiveness of noise reduction systems on Dublin's light rail system (Luas), in: 11th European Conference on Noise Control 2018 (EURONOISE), 2018, pp. 1337-1344.

[19] J.W. Verheij, Inverse and reciprocity methods for machinery noise source characterization and sound path quantification. Part 2: transmission paths. International Journal of Acoustics and Vibration, 2 (1997), 103-112.

[20] H. Jeong, A numerical investigation of noise mitigation for railway track. $\mathrm{PhD}$ thesis, University of Southampton, 2019.

[21] ISO 3095:2013, Acoustics - Railway applications - Measurements of noise emitted by railbound vehicles, International Organization for Standardization, Geneva, 2013.

[22] X. Zhang, G. Squicciarini, D.J. Thompson, Sound radiation of a railway rail in close proximity to the ground. Journal of Sound and Vibration, 326 (2016), 111-124.

[23] X. Zhang, D.J. Thompson, E. Quaranta, G. Squicciarini, An engineering model for the prediction of the sound radiation from a railway track. Journal of Sound and Vibration, 461 (2019), 114921.

[24] D.J. Thompson, B. Hemsworth, N. Vincent, Experimental validation of the TWINS prediction program for rolling noise, part 1: description of the model and method. Journal of Sound and Vibration, 193 (1996), 123-135.

[25] ISO 3095:2013, Acoustics - Railway applications - Measurements of noise emitted by railbound vehicles, International Organization for Standardization, Geneva, 2013. 